\title{
Optimal timing of doses of chenic acid in patients with gall stones
}

\author{
D P MAUDGAL, R BIRD, T C NORTHFIELD
}

British Medical fournal, 1979, 1, 922-923

\section{Summary and conclusions}

Sixteen patients with gall stones were treated with chenic acid (14-16 $\mathrm{mg} / \mathrm{kg} / \mathrm{day})$ given at three different times in random order for one month each. Before treatment the mean ( \pm SE of mean) cholesterol saturation index (SI) of fasting gall-bladder bile was 1.28 \pm 0.06 . During bedtime administration of chenic acid the mean SI fell to $0.78 \pm 0.04$, which was significantly lower than that obtained with administration in the morning (0.92 \pm 0.05$)$ or with three divided doses at mealtimes (0.92 \pm 0.04$)$. The bile remained supersaturated in seven patients when they received a single morning dose, in five patients when they received mealtime doses, but in only one patient when a single bedtime dose was given. There was no significant difference in side effects between the three different dose timings, or in the proportion of bile acids present in the bile as chenic acid.

This enhanced effect obtained with bedtime administration may be due to the enterohepatic circulation of bile acids being maintained during overnight fasting.

\section{Introduction}

Chenodeoxycholic (chenic) acid given by mouth renders fasting gall-bladder bile unsaturated with cholesterol and induces the dissolution of cholesterol gall stones. ${ }^{12}$ It takes six to 12 months to dissolve small gall stones, and longer for large stones. ${ }^{3}$ Some patients do not respond to the recommended dose of $15 \mathrm{mg} / \mathrm{kg} /$ day given at mealtimes because their bile remains supersaturated. ${ }^{4} \mathrm{~A}$ higher dose increases the response rate ${ }^{4}$ but also increases the incidence of diarrhoea. ${ }^{5}$ It is therefore important to find methods of enhancing the effect of treatment with chenic acid in the hope of increasing the response rate, and also the dissolution rate in those who do respond.

Giving chenic acid with meals reduces biliary cholesterol secretion $^{6}$ but does not abolish the secretion of supersaturated bile that results from interrupting the enterohepatic circulation of bile acids during overnight fasting. ${ }^{6}$ The hypothesis underlying the current study is that giving chenic acid at bedtime should maintain the enterohepatic circulation of bile acids by ensuring the gradual release of chenic acid from the stomach into the small intestine during the night and thus prevent secretion of supersaturated bile. We have, therefore, compared the effect of a single bedtime dose on the cholesterol saturation of fasting gall-bladder bile in 16 patients with gall stones with the effect of the same total daily dose of chenic acid given in divided doses at mealtimes and as a single morning dose.

Norman Tanner Gastroenterology Unit, St James's Hospital, and Department of Medicine, St George's Hospital Medical School, London SW17 ORE

D P MAUDGAL, MRCP, senior medical registrar

R BIRD, technical assistant

T C NORTHFIELD, MD, FRCP, consultant physician and senior lecturer

\section{Patients and methods}

We studied 16 patients (eight men aged 45-79 years and eight women aged 36-64 years). All had gall stones visible on oral cholecystography and normal gall-bladder opacification. Written informed consent was obtained from each patient. A sample of fasting gallbladder bile was obtained before treatment. Every patient then received chenic acid, in 125-mg gelatin capsules in a dose of 14-16 $\mathrm{mg} / \mathrm{kg} /$ day, ${ }^{1}$ at three different times for one month each in random order-that is, a single morning dose before breakfast, a single bedtime dose, and three divided doses with meals. The daily dose of chenic acid was the same in each of the three regimens. Further bile samples were collected at the end of one, two, and three months' treatment. At each visit the patients gave a report of bowel frequency over the previous week.

Bible sampling and analysis-After an overnight fast a duodenal tube was passed under $x$-ray control, and gall-bladder contraction was stimulated by intravenous infusion of 75 Ivy dog units of cholecystokinin (Karolinska Institute, Stockholm). Bile-rich duodenal fluid was aspirated and $10 \mathrm{ml}$ of the most concentrated aspirate saved for analysis. Cholesterol concentrations were measured by the cholesterol oxidase method of Roda $\mathrm{et} a l,{ }^{7}$ and phosphorus concentrations by the method of Bartlett. ${ }^{8}$ The total bile acid concentration was measured enzymatically using $3 \alpha$-hydroxysteroid dehydrogenase by the method of Talalay ${ }^{9}$ modified by Admirand and Small. ${ }^{11}$ The proportion of bile acids present as chenic acid was determined by thin-layer chromatographic separation of dihydroxy and trihydroxy bile acids, followed by $3 \alpha$-hydroxysteroid ${ }^{11}$ and $7 \alpha$-hydroxysteroid dehydrogenase enzyme assays. ${ }^{12}$ The cholesterol saturation index (SI) was calculated using the polynomial equation developed by Thomas and Hofmann, ${ }^{13}$ based on limits of cholesterol solubility defined by Hegardt and Dam ${ }^{14}$ and Holzbach et al. ${ }^{15}$

Statistical analysis was carried out by Student's $t$ test and the Wilcoxon signed-rank sum test for paired samples.

\section{Results}

Before treatment the fasting gall-bladder bile was supersaturated with cholesterol in all 16 patients (figure). The bile became unsaturated

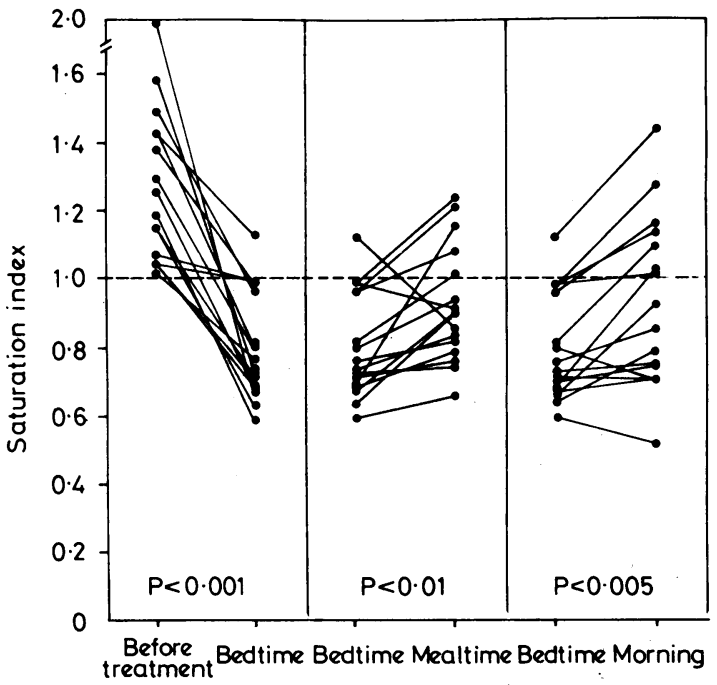

Cholesterol saturation index of fasting gall-bladder bile before and during treatment with chenic acid (14-16 $\mathrm{mg} / \mathrm{kg} /$ day), given in random order for one month each at three different times (a single bedtime dose, mealtime doses, and a single morning dose). 
in 15 of the patients when they received a single bedtime dose of chenic acid, in nine with the single morning dose, and in 11 with the three divided doses at mealtimes. The mean ( \pm SE of mean) SI fell from $1.28 \pm 0.06$ to $0.78 \pm 0.04(P<0.001)$ with a single bedtime dose. This effect was greater than that with a single morning dose (SI $0.92 \pm 0.05 ; \mathrm{P}<0.005)$ or with divided doses at mealtimes (SI $0.92 \pm$ $0.04 ; \mathrm{P}<0.01)$.

The percentage of the total bile acids in bile present as chenic acid was $28 \cdot 2 \pm 2 \cdot 74 \%$ before treatment. During treatment it rose $(P<0.001)$ to $82 \cdot 9 \pm 2 \cdot 7 \%$ with a single bedtime dose, to $81 \cdot 9 \pm 2 \cdot 2 \%$ with a single morning dose, and to $83 \cdot 0 \pm 2 \cdot 4^{\circ} \%$ with three divided doses at mealtimes. There was no significant difference in percentage chenic acid between the three dose timings.

Daily bowel frequency during the week before treatment was $1.12 \pm 0.11$ movements/day. It was $1.75 \pm 0.32$ movements/day $(\mathrm{P}<0.02)$ with a single morning dose, $1.92 \pm 0.35$ movements/day $(\mathrm{P}<0.01)$ with divided doses with meals, and $1.60 \pm 0.19$ movements/ day $(P<0.05)$ with a single bedtime dose. There was no significant difference in bowel frequency between the three regimens.

\section{Discussion}

We have shown that administering chenic acid as a single bedtime dose is more effective in lowering the mean SI of fasting gall-bladder bile than the conventional regimen of divided doses at mealtimes. Furthermore, unsaturation of bile, an essential prerequisite for gall-stone dissolution, was achieved in all but one patient with bedtime administration and in only 11 out of 16 patients with the mealtime regimen. This improvement in response rate was not accompanied by any increase in bowel frequency. The additional reduction in the SI obtained with a single bedtime dose may also speed the dissolution rate. Bell et al, ${ }^{16}$ in studies using bile from the rhesus monkey, showed that the rate of dissolution of gall stones depends on the degree of cholesterol unsaturation of the bile. Clinical trials are necessary to confirm this effect in man.

Conventional administration of chenic acid at mealtimes decreases biliary cholesterol secretion ${ }^{6}{ }^{17}$ and thus renders fasting gall-bladder bile unsaturated in cholesterol. The degree of unsaturation is proportional to the percentage of chenic acid in the bile. ${ }^{18}$ The greater reduction in the cholesterol SI that occurred with bedtime administration was not due to an exaggeration of this effect resulting from the slightly shorter time interval between administration of the chenic acid and bile sampling, since the percentage of chenic acid in the bile was not increased at the time of the sampling. Furthermore, the effect on the SI of giving chenic acid at mealtimes persists for one to two weeks after stopping treatment. ${ }^{19}$

Bedtime administration must implicate some additional mechanism of action. We suggest that this enhanced effect is due to the enterohepatic circulation of bile acids being maintained during overnight fasting.

We are grateful to Weddel Pharmaceuticals and to the Medical Research Committee, St George's Hospital Medical School, for financial support.

Requests for reprints should be addressed to TCN, Department of Medicine 2, St George's Hospital Medical School, Cranmer Terrace, London SW17 ORE.

\section{References}

${ }^{1}$ Bell, G D, Whitney, B, and Dowling, R H, Lancet, 1972, 2, 1213.

2 Danzinger, R G, et al, New England fournal of Medicine, 1972, 186, 1.

${ }^{3}$ Iser, J H, et al, New England Fournal of Medicine, 1975, 293, 379.

${ }^{4}$ Iser, J H, Maton, P M, and Dowling, R H, British Medical Fournal, 1978, 1, 1185.

5 Bateson, M C, et al, Lancet, 1975, 1, 1111

${ }^{6}$ Northfield, T C, et al, Gut, 1975, 16, 12.

${ }^{7}$ Roda, A, et al, Clinica Chimica Acta, 1975, 64, 337.

${ }^{8}$ Bartlett, G R, Fournal of Biological Chemistry, 1959, 234, 466.

9 Talalay, P, in Methods of Biochemical Analysis, ed D Glick, vol 8, p 119. New York, New York Interscience, 1960.

${ }^{10}$ Admirand, W H, and Small, D M, fournal of Clinical Investigation, $1968,47,1043$

11 Bruusgaard, A, Clinica Chimica Acta, 1970, 28, 495.

12 Haslewood, G A D, Murphy, G M, and Richardson, J M, Clinical Science, $1973,44,95$.

13 Thomas, P J, and Hofmann, A F, Gastroenterology, 1973, 65, 698.

${ }^{14}$ Hegardt, F G, and Dam, H, Zeitschrift für Ernährungswissenschaft, 1971, 10, 223.

15 Holzbach, R T, et al, fournal of Clinical Investigation, 1973, 52, 1967.

16 Bell, G D, et al, Gut, 1972, 13, 836.

17 Adler, R D, et al, Gastroenterology, 1975, 68, 326.

18 Thistle, J L, et al, American fournal of Digestive Diseases, 1977, 22, 1.

19 Iser, J H, Murphy, G M, and Dowling, R H, Gut, 1977, 18, 7.

(Accepted 12 February 1979)
ONE HUNDRED YEARS AGO This man is of immense size, tall, stout, and weighing about twenty stones. He is excitable and active, and has been worried of late with reverses. He eats largely and drinks deeply. He has been much exposed to cold and wet, and, after more than usual exposure, he came in with a big swelling on the left side of the anus, extending outwards to the tuberosity, forwards to and across the perinaeum, and backwards to the sacrum; it was pale, hard, and painful. Fever and extreme prostration were present. Iodine liniment was freely applied in large patches to the neighbouring skin. Incisions were also made into the swelling, and revealed most strikingly a large black mass of dead tissue, without any suppuration. There have been slight relapses, but in each relapse the black masses have become smaller. There has been no suppuration, and death has been confined to cellular tissue.

This typical but mild case (mild, I believe, from early and active counterirritation) suggests several topics for brief comment. The disease is essentially idiopathic. A kind of creeping cellulitis, not attended with much swelling, in rare cases, follows operations on the pelvic structures. In this, and in other cases which I shall briefly cite, there have been no operation and no injury.

The few cases I have seen have been in big, heavy, middle-aged men; in men of continual activity and excitable temperament, always working or travelling, or eating or drinking; in men who combined two bad habits-eating much and drinking much; in men sufficiently wellto-do to indulge at will, and who firmly believed that excess of work needed excess of victuals and liquor; in men who were indifferent to weather, and had been notably exposed to cold and wet. All the cases I have seen occurred in cold weather, and I believe they are more frequent with us in the exposed high table-land of mid-England. It is not probable that all the favouring conditions, which have been combined with singular uniformity in my cases, will always be found together. Some causes may be powerful, others feeble, others absent. Probably, idiopathic cellulitis occurs in men, chiefly because men combine the several conditions which lead to it. Freely drinking women rarely eat excessively. It is a matter of wonder, not confined to the public, that "drinkers" should live so long, seeing that they frequently take little solid food. In truth, they live so long because they eat so little. Singularly little food supports the adult. Take much food, and at the same time check metamorphosis with copious alcohol, and you lay a train for very certain pathological explosions. One of these explosions, and a dangerous one, is cellulitis around the rectum. The pale, hard, slightly lobed, extremely prominent swelling projecting between the big buttocks of a big man is not easy to describe. It may begin anywhere in the vicinity of the rectum-around the tube or near the surface; if it begin deeply, is quickly comes to the surface; if it begin under the skin, it soon extends deeply. Its deep position is sometimes known by the effects of pressure, as on the sacral plexus. In a somewhat similar disease-cellulitis of the neck-I have known paralysis of one arm appear a day or two before the dense collar in front of the neck.

The progress of the disease is very rapid. The skin over the swelling, if not cut by the surgeon, quickly melts away, and discloses a mass of dead, black, foetid tissue, but, as a rule, no suppuration. The slough comes away rather slowly; a cavity, usually of extreme size, is left, which closes tardily, and leaves, curiously, no fistula, as does the ischio-rectal abscess. (British Medical fournal, 1879.) 